\title{
Loss at 16q22.1 identified as a risk factor for intrahepatic recurrence in hepatocellular carcinoma and screening of differentially expressed genes
}

\author{
L. $\mathrm{CHEN}^{1,2}$, Z. Z. ZHU $\mathrm{ZH}^{2,3, *}$, S. F. LIU ${ }^{4}$, X. WAN ${ }^{2,3}$, B. J. WEN ${ }^{2}$, H. JIANG ${ }^{5}$, J. ZHU ${ }^{6}$, W. M. CONG
}

${ }^{1}$ Ningbo University School of Medicine, Ningbo, China; ${ }^{2}$ Department of Oncology, No. 113 Hospital of People's Liberation Army, Ningbo, China; ${ }^{3}$ Ningbo Key Lab of Cancer Risk and Intervention, Ningbo, China; ${ }^{4}$ Parexel International, Shanghai, China; ${ }^{5}$ Department of Statistics, Northwestern University, Evanston, IL, USA; ${ }^{6}$ Tongji Medical College, Huazhong University of Science and Technology, Wuhan, China; ${ }^{7}$ Department of Pathology, Eastern Hepatobiliary Surgery Hospital, Second Military Medical University, Shanghai, China

*Correspondence: zzzhu1170@yeah.net

Received June 27, 2015 / Accepted August 10, 2015

\begin{abstract}
Copy number alteration (CNA) of chromosome 16, a frequent genetic event in tumors including hepatocellular carcinoma (HCC), has been associated with HCC etiology of hepatitis B virus (HBV) and with clinical outcomes in multiple types of cancer. This study identified CNAs in chromosome 16 in relation to intrahepatic recurrence of HCC in a population with high HBV prevalence, and further screened for differentially expressed genes in recurrence-related CNAs. Array comparative genomic hybridization and expression arrays were used to detect CNAs and gene expression differences, respectively. The associations between CNAs and intrahepatic recurrence were analyzed on 66 patients, follow-up period of 3-73 months. One hundred and nine cases were further evaluated regarding the differentially expressed genes. Losses at $16 \mathrm{q}$ and $16 \mathrm{p}$ were detected in $62.1 \%$ and $51.5 \%$ of the 66 cases, respectively. The most recurrent CNAs (with frequency $>20 \%$ ) were losses at 16p13.3-13.2, 16p13.11, 16q11.2-22.1, 16q22.1, 16q22.2-24.2 and 16q24.2. Of the CNAs, 16q22.1 loss was significantly associated with unfavorable intrahepatic recurrence-free survival $(P=0.025)$. Multivariate Cox analysis identified 16q22.1 loss as an independent risk factor for intrahepatic recurrence $(\mathrm{HR}=2.32,95 \% \mathrm{CI}=1.26-4.27)$. A panel of 21 genes, including TRADD, PSMB10, THAP11, CTCF and ESRP2, were significantly downregulated in HCCs with $16 \mathrm{q} 22.1$ loss compared to those without the loss. These results suggest that loss at 16q22.1 was associated with increased risk for intrahepatic recurrence of HCC, at least in the HBV-prevalence population. Multiple downregulated genes correlated with the loss were screened.
\end{abstract}

Key words: chromosome 16, copy number alteration, gene expression, hepatocellular carcinoma, intrahepatic recurrence

Hepatocellular carcinoma (HCC) is one of the most frequently occurring human cancers worldwide and since the 1990s has been ranked as the second leading cause of cancer death in China, where most of HCCs correlate with chronic hepatitis B virus (HBV) etiology [1]. Surgical resection remains the first-line treatment for operable HCC nowadays, whereas the greatest problem plaguing the potential curative treatment is the high rate of postoperative intrahepatic recurrence [2]. However, predictive factors for development of intrahepatic recurrence continue to be incompletely defined [2,3]. Thus, biomarker discovery of intrahepatic recurrence will likely play an essential role in improving prognosis of patients with HCC by guiding treatment decisions.

DNA copy number alteration (CNA), i.e., gain and loss of segmental DNA, is a major feature of solid tumors including
HCC [4]. These CNAs could result in aberrant expression of cancer-related genes and thus play an important role in tumor development, progression and patient outcome [4]. Previous studies on HCC have mapped recurrent CNAs to chromosomes $1 \mathrm{q}, 4 \mathrm{q}, 6 \mathrm{p}, 8 \mathrm{p}, 8 \mathrm{q}, 13 \mathrm{q}, 16 \mathrm{p}, 16 \mathrm{q}, 17 \mathrm{p}$, and 17q, but little is known about their associations with intrahepatic recurrence [5-10]. CNAs mapping to chromosome 16 are of particular interest because of overrepresentation in tumors, location of multiple genes implicated in tumor progression [11-13], and correlation with unfavorable outcomes in multiple types of cancer [14-20], with conflicting results [21-24]. Most notably, losses at 16p and $16 \mathrm{q}$ have been associated with the HCC etiology of HBV $[7,8]$. However, the relationship between CNAs in chromosome 16 and intrahepatic recurrence in HCC, particularly in the population with high HBV prevalence, remains unclear $[9,10]$. 
In the present study, we determined whether recurrent CNAs in chromosome 16 were associated with intrahepatic recurrence in HCC patients in a Chinese population. The differentially expressed genes in the same direction with CNAs (i.e. upregulation and gain or downregulation and loss), within the potentially recurrence-related CNAs, were further identified by a simultaneous array comparative genomic hybridization (CGH) and expression analysis.

\section{Patients and methods}

Patients and tissue samples. Tumor specimens were obtained from surgical resections at Eastern Hepatobiliary Surgery Hospital, Second Military Medical University, Shanghai, China. All patients were ethnic Han Chinese, and none had received radiation therapy or chemotherapy before surgery. Final diagnosis of $\mathrm{HCC}$ was pathologically confirmed and only patients with samples containing a minimum of $80 \%$ tumor cells were finally enrolled. Tumor specimens were collected from resected liver in $30 \mathrm{~min}$, immediately frozen in liquid nitrogen, and kept at $-80^{\circ} \mathrm{C}$ until DNA/RNA extraction. Written informed consent was obtained from all participants, and the study protocol was approved by the Institutional Review Board of the hospital.

Totally 179 patients with HCC were investigated. Group I consisted of 66 patients, enrolled between December 2007 and January 2008, for identification of recurrent CNAs in association with intrahepatic recurrence. All of the 66 patients had follow-up visits. In the second group (II), 113 patients enrolled between January and March 2007 were investigated for identification of differentially expressed genes within recurrence-related CNAs. For group II, experimental analysis was unsuccessful on 8 cases for array CGH and 5 cases for gene expression, leaving a number of 100 study subjects with matched array CGH and expression data. Nine patients in Group I also had matched array CGH and expression data, and thus a total of 109 subjects were included in the final analysis of the identification of differentially expressed genes.

Follow-up. All the 66 HCC patients in Group I were followed up, and the median follow-up time was 39 months (range, 3-73 months) with 2586 months of total analysis time. After surgery, all patients were screened at regular intervals for the development of intrahepatic recurrence by clinical examination, serum alpha fetoprotein (AFP), various imaging modalities, and/or pathological examination. Imaging modalities were performed once every three to six months, or when necessary. Serum AFP was measured once every month. Intrahepatic recurrence-free survival was expressed as the number of months from the date of surgery to the date of diagnosis of intrahepatic recurrence.

Array CGH analysis for CNAs. Genomic DNA in tumors was extracted using the Genomic DNA purification Kit (Qiagen, Valencia, CA, USA). Array CGH analysis for CNAs in chromosome 16 was performed using the high-resolution Agilent Human Genome Microarray Kit 244K (Hu-244A,
Agilent Technologies), which has an average probe spacing of $12.9 \mathrm{~Kb}$ for chromosome 16. Labeling and hybridization were performed according to the standard protocol provided by Agilent (Protocol v4.0, June 2006). Arrays were scanned using Agilent G2565BA DNA Microarray Scanner, and further extracted using Feature Extraction software 9.5. Circular binary segmentation (CBS) algorithm was performed for each of the multiple samples independently and separately using the R package "DNAcopy". For each region, the segmented $\log _{2}$ ratios were assigned to be the average $\log _{2}$ ratios of the contained probes in that region. Copy number changes were characterized as reported [25]. At least five consecutive probes altered in the same polarity were required to define a region. An absolute $\log _{2}$ ratio $>0.5$ was used as the threshold for the gain or loss in DNA copy number for each region. The probe sequences and gene annotations are based on NCBI Build 35 of the human genome and UCSC version hg17 released in May 2004.

Gene expression analysis. Gene expression level in tumors was measured using Affymetrix GeneChip Human Genome U133 Plus 2.0 arrays (Affymetrix, Santa Clara, CA). Sample processing and labeling were performed according to the protocol provided by the Affymetrix. In brief, total RNA was extracted and subsequently purified using RNeasy Mini kit (Qiagen, Valencia, CA). Three micrograms of total RNA was reverse transcribed to cDNA using One-Cycle cDNA Synthesis Kit (Affymetrix). Biotin-labeling of antisense cDNA was carried out using IVT Labeling Kit (Affymetrix). The labeled and fragmented cDNA was hybridized to U133 Plus 2.0 arrays for 16 hours at $45^{\circ} \mathrm{C}$, followed by automated array washing and staining procedures. The arrays were scanned using Gene array Scanner3000 7G and images were analyzed using GeneChip Operating Software (GCOS; Affymetrix). Data processing was done using Robust Multi-array Analysis (RMA) algorithm implemented in the R package "affy". Probe sets were mapped to the human genome according to the hg17 Build 35 from the National Center for Biotechnology Information (NCBI) Ensembl database and the University of California at Santa Cruz Genome Bioinformatics database Genome Browser.

Statistical analysis. The log-rank test was used to compare the intrahepatic recurrence-free survival between patient groups according to specific CNAs (no, yes), as well as age ( $\leq 50$ years, $>50$ years), sex, chronic HBV infection (negative, positive), serum AFP ( $\leq 20 \mu \mathrm{g} / \mathrm{L},>20 \mu \mathrm{g} / \mathrm{L})$, Child-Pugh classification (A, B), liver cirrhosis (no, yes), tumor number (single, multiple), tumor size $(\leq 5 \mathrm{~cm},>5 \mathrm{~cm})$, vascular invasion (no, yes), Edmondson-Steiner grade (II, III), tumor encapsulation (present, absent), or tumor-node-metastasis (TNM) stage (I/II, III). The Kaplan-Meier method was used to estimate survival curves. Cox proportional hazard model was performed to determine independent CNAs for prediction of intrahepatic recurrence. Variables statistically significant in univariable analyses, including tumor number, vascular invasion, tumor encapsulation, and TNM stage, were included in the multivariable analysis. As a sensitivity 
analysis, we further adjusted for age, sex, chronic HBV infection, serum AFP, Child-Pugh classification, liver cirrhosis, tumor size, and Edmondson-Steiner grade. This sensitivity analysis did not yield meaningful differences (data not shown). Mann-Whitney $U$ test was used to compare the gene expression levels between HCCs with and without CNA. The false discovery rate (FDR) controlling procedure was used to correct for the multiple comparisons and a $q$ value $<0.05$ was taken as a measure of significance. All statistical analyses were performed with Stata 10.1 (Stata Corporation, College Station, TX) and $P$ values $<0.05$ were considered statistically significant.

\section{Results}

Associations between clinicopathological features and intrahepatic recurrence. The associations of clinicopathological features with intrahepatic recurrence on $66 \mathrm{HCC}$ patients in Group I were shown in Table 1. Multiple tumor $(P=0.0001)$, vascular invasion $(P=0.006)$, absence of tumor encapsulation $(P=0.025)$, and advanced TNM stage $(P=0.0003)$ were significantly associated with intrahepatic recurrence. No significant association was observed between age, sex, chronic HBV infection, serum AFP, Child-Pugh classification, liver cirrhosis, tumor size, or Edmondson-Steiner grade and intrahepatic recurrence.

CNAs in chromosome 16 correlated with intrahepatic recurrence. Of the $66 \mathrm{HCC}$ cases, 12 showed no copy number change in chromosome 16 . The most common alteration was copy number loss of $16 \mathrm{q}(41 / 66 ; 62.1 \%)$, either whole arm loss $(14 / 66 ; 21.2 \%)$, or partial loss $(27 / 66 ; 40.9 \%)$. Whole arm and partial losses of $16 \mathrm{p}$ were observed in 1 case (1.5\%) and 33 cases (50.0\%), respectively. The most recurrent CNAs (with frequency $>20 \%$, Table 2) were losses at 16p13.3-13.2, 16p13.11, 16q11.2-22.1, 16q22.1, 16q22.2-24.2, and 16q24.2. Survival analysis showed that 16q22.1 loss was significantly

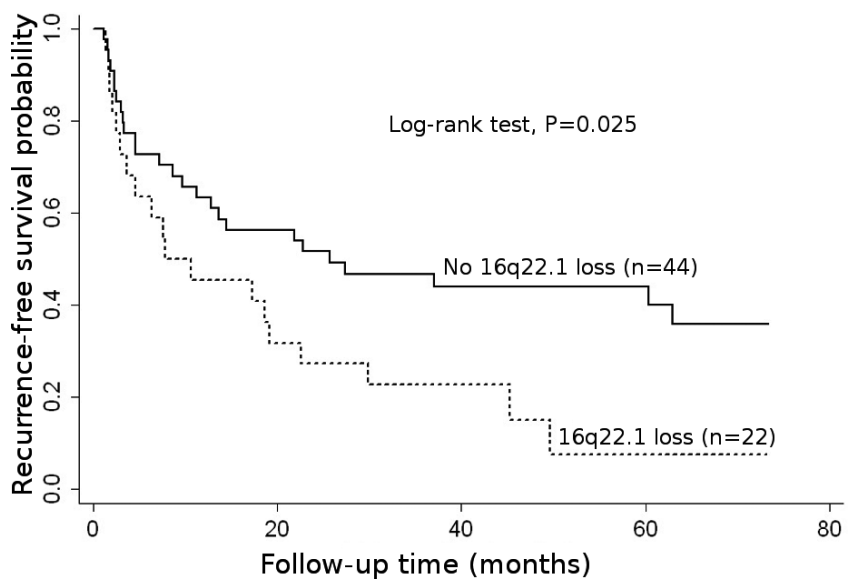

Figure 1. Intrahepatic recurrence-free survival of patients with hepatocellular carcinoma according to the status of $16 \mathrm{q} 22.1$ loss. associated with unfavorable intrahepatic recurrence-free survival $(P=0.025$, Fig. 1$)$. Multivariate Cox analysis showed that $16 \mathrm{q} 22.1$ loss was an independent risk factor for intrahepatic recurrence (hazard ratio $(\mathrm{HR})=2.32,95 \%$ confidence interval $(\mathrm{CI})=1.26-4.27, P=0.007$, Table 2 ). Further analysis of 16q22.1 loss in relation to intrahepatic recurrence was repeated using only HBV-positive cases $(n=63)$, and in this analysis a similar risk estimate was observed (data not shown). No significant association was observed between losses at 16p13.3-13.2, 16p13.11, 16q11.2-22.1, 16q22.2-24.2 or 16q24.2 and intrahepatic recurrence (Table 2).

Table 1. Association of clinicopathological features with intrahepatic recurrence of hepatocellular carcinoma

\begin{tabular}{|c|c|c|c|c|}
\hline & No. $(\%)$ & $\begin{array}{c}\text { Disease-free } \\
\text { person-months }\end{array}$ & $\begin{array}{c}\text { Recurrence } \\
\text { No. }\end{array}$ & $P^{\dagger}$ \\
\hline \multicolumn{5}{|l|}{ Age (years) } \\
\hline$\leq 50$ & $32(48.5)$ & 848.7 & 20 & \\
\hline$>50$ & $34(51.5)$ & 867.1 & 25 & 0.589 \\
\hline \multicolumn{5}{|l|}{ Sex } \\
\hline Female & $18(27.3)$ & 508.8 & 12 & \\
\hline Male & $48(72.7)$ & 1207.0 & 33 & 0.891 \\
\hline \multicolumn{5}{|c|}{ Chronic HBV infection } \\
\hline Negative & $3(4.5)$ & 97.4 & 2 & \\
\hline Positive & $63(95.5)$ & 1618.4 & 43 & 0.854 \\
\hline \multicolumn{5}{|l|}{$\operatorname{AFP}(\mu \mathrm{g} / \mathrm{L})$} \\
\hline$\leq 20$ & $20(30.3)$ & 534.3 & 13 & \\
\hline$>20$ & $46(69.7)$ & 1181.5 & 32 & 0.684 \\
\hline \multicolumn{5}{|c|}{ Child-Pugh classification } \\
\hline $\mathrm{A}$ & $55(83.3)$ & 1467.5 & 37 & \\
\hline B & $11(16.7)$ & 248.3 & 8 & 0.462 \\
\hline \multicolumn{5}{|c|}{ Liver cirrhosis } \\
\hline No & $27(40.9)$ & 885.2 & 18 & \\
\hline Yes & $39(59.1)$ & 830.6 & 27 & 0.360 \\
\hline \multicolumn{5}{|c|}{ Tumor number } \\
\hline Single & $49(74.2)$ & 1535.3 & 30 & \\
\hline Multiple & $17(25.8)$ & 180.5 & 15 & $<0.001$ \\
\hline \multicolumn{5}{|c|}{ Tumor size $(\mathrm{cm})$} \\
\hline$\leq 5$ & $28(42.4)$ & 796.6 & 17 & \\
\hline$>5$ & $38(57.6)$ & 919.2 & 28 & 0.210 \\
\hline \multicolumn{5}{|c|}{ Vascular invasion } \\
\hline No & $32(48.5)$ & 1087.4 & 18 & \\
\hline Yes & $34(51.5)$ & 628.4 & 27 & 0.006 \\
\hline \multicolumn{5}{|c|}{ Edmondson-Steiner grade } \\
\hline II & $14(21.2)$ & 399.6 & 10 & \\
\hline III & $52(78.8)$ & 1316.2 & 35 & 0.607 \\
\hline \multicolumn{5}{|c|}{ Tumor encapsulation } \\
\hline Present & $23(34.8)$ & 874.9 & 14 & \\
\hline Absent & $43(65.2)$ & 840.9 & 31 & 0.025 \\
\hline \multicolumn{5}{|c|}{ TNM stage } \\
\hline $\mathrm{I} / \mathrm{II}$ & $41(62.1)$ & 1367.3 & 24 & \\
\hline III & $25(37.9)$ & 348.4 & 21 & $<0.001$ \\
\hline
\end{tabular}

AFP, alpha fetoprotein; HBV, hepatitis B virus; TNM, tumor-node-metastasis. ${ }^{\dagger}$ Log-rank test. 
Intrahepatic recurrences could be early ( $\leq 2$ years) and late ( $>2$ years) recurrences, and thus we further analyzed the association between 16q22.1 loss and intrahepatic recurrence according to the early and late type. The results showed no major difference in risk estimate for the early recurrence (n $=37$ ) from the result on all recurrent cases, with no change in statistical significance $(\mathrm{HR}=2.35,95 \% \mathrm{CI}=1.17-4.72, P=$ $0.016)$. However, for the late recurrence $(\mathrm{n}=8)$, a nonsignificant 3.20-fold $(95 \% \mathrm{CI}=0.65-15.77, P=0.153)$ increased risk was observed for HCCs with 16q22.1 loss as compared to without.
Downregulated genes in 16q22.1 loss correlated with intrahepatic recurrence. To explore the downregulated genes of the 16q22.1 loss correlated with intrahepatic recurrence, expression levels of a total of 54 known genes that fell within the lost region were compared between HCCs with and without 16q22.1 loss, on 109 HCCs with matched array CGH and expression data. With the $q$ value cutoff of 0.05 , a panel of 21 genes including TRADD, PSMB10, THAP11, CTCF and ESRP2, was identified to be significantly downregulated in HCCs with loss $(\mathrm{n}=33)$ compared to those without $(\mathrm{n}=$ 76, Table 3).

Table 2. Recurrent losses in chromosome 16 and associations with intrahepatic recurrence of hepatocellular carcinoma

\begin{tabular}{lccccc}
\hline Cytoband $^{\dagger}$ & No. $(\%)$ & Map position $\left(\right.$ start - end) ${ }^{\dagger}$ & Size $(\mathrm{bp})$ & $P^{\ddagger}(95 \% C I)^{\ddagger}$ \\
\hline $16 \mathrm{p} 13.3-13.2$ & $17(25.8)$ & $5714603-7304741$ & 1590139 & $1.02(0.51-2.05)$ & 0.949 \\
$16 \mathrm{p} 13.11$ & $29(43.9)$ & $14956252-14997419$ & 41168 & $1.40(0.73-2.70)$ & 0.309 \\
$16 q 11.2-22.1$ & $24(36.4)$ & $45058242-65500521$ & 20442280 & $1.60(0.87-2.97)$ & 0.133 \\
$16 q 22.1$ & $22(33.3)$ & $65503935-66951192$ & 1447258 & $2.32(1.26-4.27)$ & 0.007 \\
$16 q 22.2-24.2$ & $27(40.9)$ & $69763173-85979029$ & 16215857 & $1.65(0.86-3.20)$ & 0.134 \\
$16 q 24.2$ & $32(48.5)$ & $85984988-86032082$ & 47095 & $1.04(0.56-1.92)$ & 0.905 \\
\hline
\end{tabular}

HR, hazard ratio; CI, confidence interval.

${ }^{\dagger}$ Cytoband and map position are based on NCBI Build 35 of the human genome and UCSC version hg17 released in May 2004.

${ }^{*}$ Adjusted by tumor number, vascular invasion, tumor encapsulation, and TNM stage.

Table 3. Significantly downregulated genes correlated with 16q22.1 loss in hepatocellular carcinomas

\begin{tabular}{|c|c|c|c|c|}
\hline Gene & Description & $\mathrm{HCC}_{\text {with }}$ loss ${ }^{\dagger}$ & HCC without loss ${ }^{\dagger}$ & $\begin{array}{l}\text { Expression re- } \\
\text { duction }(\%)^{*}\end{array}$ \\
\hline FAM96B & family with sequence similarity 96 , member B & $8.73(8.36-9.10)$ & $9.56(9.39-9.73)$ & 43.8 \\
\hline CBFB & core-binding factor, beta subunit & $7.36(6.87-7.85)$ & $8.40(8.19-8.61)$ & 51.3 \\
\hline C16orf70 & chromosome 16 open reading frame 70 & $6.77(6.46-7.08)$ & $7.59(7.42-7.76)$ & 43.4 \\
\hline TRADD & TNFRSF1A-associated via death domain & $6.46(6.25-6.67)$ & $7.20(7.07-7.33)$ & 40.1 \\
\hline ELMO3 & engulfment and cell motility 3 & $3.83(3.27-4.38)$ & $4.94(4.63-5.25)$ & 53.7 \\
\hline TMEM208 & transmembrane protein 208 & $7.92(7.53-8.31)$ & $8.79(8.64-8.94)$ & 45.2 \\
\hline ATP6V0D1 & ATPase, $\mathrm{H}+$ transporting, lysosomal $38 \mathrm{kDa}, \mathrm{V} 0$ subunit $\mathrm{d} 1$ & $7.76(7.18-8.34)$ & $8.92(8.69-9.15)$ & 55.1 \\
\hline FAM65A & family with sequence similarity 65, member A & $6.62(6.31-6.93)$ & $7.30(7.17-7.43)$ & 37.7 \\
\hline CTCF & CCCTC-binding factor (zinc finger protein) & $7.70(7.48-7.91)$ & $8.22(8.12-8.32)$ & 30.4 \\
\hline GFOD2 & glucose-fructose oxidoreductase domain containing 2 & $4.12(3.62-4.62)$ & $4.97(4.64-5.30)$ & 44.7 \\
\hline RANBP10 & RAN binding protein 10 & $5.92(5.69-6.16)$ & $6.69(6.53-6.85)$ & 41.3 \\
\hline THAP11 & THAP domain containing 11 & $6.46(6.17-6.76)$ & $7.12(6.99-7.25)$ & 36.7 \\
\hline NUTF2 & nuclear transport factor 2 & $7.00(6.75-7.26)$ & $7.68(7.53-7.83)$ & 37.5 \\
\hline EDC4 & enhancer of mRNA decapping 4 & $5.24(4.93-5.54)$ & $6.04(5.93-6.15)$ & 42.6 \\
\hline PSMB10 & proteasome (prosome, macropain) subunit, beta type, 10 & $6.31(5.77-6.86)$ & $7.54(7.34-7.73)$ & 57.2 \\
\hline DDX28 & DEAD (Asp-Glu-Ala-Asp) box polypeptide 28 & $5.40(5.03-5.76)$ & $6.20(6.06-6.34)$ & 42.8 \\
\hline DUS2L & dihydrouridine synthase 2 & $5.08(4.71-5.45)$ & $5.90(5.75-6.05)$ & 43.3 \\
\hline NFATC3 & nuclear factor of activated T-cells, cytoplasmic, calcineurin-dependent 3 & $6.12(5.89-6.36)$ & $6.85(6.69-7.01)$ & 39.7 \\
\hline ESRP2 & epithelial splicing regulatory protein 2 & $7.52(7.23-7.80)$ & $7.77(7.46-8.07)$ & 15.8 \\
\hline SLC7A6 & $\begin{array}{l}\text { solute carrier family } 7 \text { (amino acid transporter light chain, } y+L \text { system), } \\
\text { member } 6\end{array}$ & $5.22(4.66-5.78)$ & $6.29(5.97-6.62)$ & 52.4 \\
\hline SLC7A6OS & solute carrier family 7, member 6 opposite strand & $4.75(4.27-5.22)$ & $5.54(5.25-5.83)$ & 42.3 \\
\hline
\end{tabular}

HCC, hepatocellular carcinoma.

${ }^{\dagger} \log _{2}$ based mean $(95 \% \mathrm{CI})$ gene expression level.

${ }^{*}$ HCC with loss vs. HCC without loss. 


\section{Discussion}

Occurrence of intrahepatic recurrence after surgery confers unfavorable clinical prognosis in HCC [26], however little is known about the underlying genetic basis. On the basis of the integration of high-resolution array CGH findings with clinical follow-up information, we demonstrated for the first time that recurrent loss at 16q22.1 was associated with increased risk for intrahepatic recurrence. Further, a panel of 21 downregulated genes with concordant 16q22.1 loss, including tumor suppressor candidate genes such as TRADD, PSMB10, THAP11, CTCF, and ESRP2, were identified.

Two previous CGH studies on HCC have observed recurrent losses in chromosome 16, but failed to correlate with tumor recurrence $[9,10]$. However, the two studies were based on relatively small study samples (between 32 and 34 samples) and thus included less samples infected with HBV (between 14 and 20 samples), a factor correlated with high-frequency $16 \mathrm{p} / 16 \mathrm{q}$ losses in HCC $[7,8]$. In the present study, based on a relatively large study sample from a population with high HBV prevalence, we identified $16 \mathrm{q} 22.1$ loss as a risk factor for intrahepatic recurrence of HCC. Our findings suggest that 16q22.1 loss may serve as a predictive marker for intrahepatic recurrence in HCC patients, at least in the population with high HBV prevalence. It has been reported that $16 \mathrm{q}$ loss was represented in primary and recurrent HCCs with similar frequency [27], indicating that the $16 \mathrm{q}$ loss driving the recurrence process is acquired by primary tumors. In this respect, it could be speculated that determination of the status of 16q22.1 loss could be of great clinical utility for identification of the HCC patients at higher risk of developing intrahepatic recurrence, already at the time of diagnosis, which may guide clinicians to elaborate treatment strategies individually and thus improve patient survival.

Since intrahepatic recurrence after surgery could be classified into early recurrence, representing mainly intrahepatic metastasis from the primary tumor, and late recurrence, representing mainly multicentric occurrence $[28,29]$, we further examined whether the association between 16q22.1 loss and intrahepatic recurrence depended on the recurrence time of early and late type. The results showed that the significant association existed for early recurrence, but not for late recurrence. However, given that only 8 cases were included in the late recurrence type and a more pronounced, although nonsignificant, risk estimate was observed $(\mathrm{HR}=3.20$ versus 2.35 for early recurrence), further studies based on a large sample size are required to clarify the association between 16q22.1 loss and late recurrence.

Segmental DNA loss in cancer cells is one of the underlying genetic mechanisms leading to reduced expression of the genes involved. By integration of array CGH and expression data on 16q22.1 correlated with intrahepatic recurrence, we identified a panel of 21 genes showing reduced expression levels with concordant loss, including several tumor suppressor candidate genes such as TRADD, PSMB10,
THAP11, CTCF, and ESRP2. TRADD is a central adaptor in the TNFR1 signaling complex that mediates both cell death and inflammatory signals, and its downregulation has been correlated with a lower probability of relapse-free survival in breast cancer patients [30]. PSMB10, a beta subunit of the $20 \mathrm{~S}$ proteasome, consists of the immunoproteasome acting upon intensified immune response. In human papillomavirus (HPV)-negative tonsillar and base of tongue squamous cell carcinoma, absent/low fraction of PSMB10 positive cells in the cytoplasm and absent cytoplasmic staining intensity have been correlated with a higher rate of disease recurrence [31]. THAP11 is a member of the THAPs family of cellular factors that regulate transcription, cell proliferation, apoptosis and the cell cycle. In vivo study has shown its upregulation markedly inhibits growth of a number of different cancer cells $[32,33]$. THAP11 is frequently downregulated in HCC, and knockdown of THAP11 in HepG2 cells increases both cell proliferation and invasion $[33,34]$. CTCF plays diverse roles in gene regulation, imprinting, insulation, chromosomal interactions, nuclear compartmentalisation and alternative splicing, and has been found to inhibit cancer cell growth and clonogenicity [35]. CTCF has been proposed as a possible target for 16q22.1 loss in breast and prostate cancer [36]. ESRP2 belongs to the RBM family of RNA-binding proteins, and in vivo data have suggested that its downregulation is restricted to cells that acquire a motile phenotype during cancer invasion [37]. In fact, the simultaneous downregulation of these probable target genes in 16q22.1 may represent the actual mechanism used by the cancer cell to achieve intrahepatic recurrence potential in HCC.

Several limitations should be noted in our study. Firstly, most of HCC cases investigated in the present study were HBV positive, which might make the results less applicable to HCC with other etiologies such as HCV infection and alcohol intake since $16 \mathrm{q}$ loss pattern have been shown to be distinct in HCCs of differing etiologies $[7,8]$. Secondly, the downregulated genes screened by expression array were not validated by other methods. However, the gene expression profile from Affymetrix array analysis we used has been replicated in quantitative PCR analysis in previous studies $[38,39]$. In this context, validation of the downregulated genes correlated with 16q22.1 loss in independent groups of HCC patients merit further investigations. Thirdly, most of samples for expression array (100/109, 91.7\%) lacked follow-up data, which hindered our ability to examine the association between expression levels of the downregulated genes and intrahepatic recurrence.

In conclusion, we showed that 16q22.1 loss in HCC was associated with increased risk for intrahepatic recurrence, at least in the HBV prevalence population. Multiple downregulated genes correlated with the loss, including TRADD, PSMB10, THAP11, CTCF and ESRP2 were screened. Validation studies on the predictive value of 16q22.1 loss in intrahepatic recurrence, and functional experiments on the downregulated genes are needed. 
Acknowledgements: This work was supported by the Medical Science and Technology Innovation Fund of PLA, Nanjing branch, China (No.14ZD07; No.08MA023), and Ningbo Nature Science Foundation Program (No.2009A610126).

\section{References}

[1] TORRE LA, BRAY F, SIEGEL RL, FERLAY J, LORTETTIEULENT J, et al. Global cancer statistics, 2012. CA Cancer J Clin 2015; 65: 87-108. http://dx.doi.org/10.3322/caac.21262

[2] COLECCHIA A, SCHIUMERINI R, CUCCHETTI A, CESCON M, TADDIA M, et al. Prognostic factors for hepatocellular carcinoma recurrence. World J Gastroenterol 2014; 20: 5935-50. http://dx.doi.org/10.3748/wjg.v20.i20.5935

[3] COMBESCURE C, FOUCHER Y, JACKSON D. Meta-analysis of single-arm survival studies: a distribution-free approach for estimating summary survival curves with random effects. Stat Med 2014; 33: 2521-37. http://dx.doi.org/10.1002/sim.6111

[4] BEROUKHIM R, MERMEL CH, PORTER D, WEI G, RAYCHAUDHURIS, et al. The landscape of somatic copy-number alteration across human cancers. Nature 2010; 463: 899-905. http://dx.doi.org/10.1038/nature08822

[5] OUYANG L, LEE J, PARK CK, MAO M, SHI Y, et al. Wholegenome sequencing of matched primary and metastatic hepatocellular carcinomas. BMC Med Genomics 2014; 7: 2. http://dx.doi.org/10.1186/1755-8794-7-2

[6] HUANG J, SHENG HH, SHEN T, HU YJ, XIAO HS, et al. Correlation between genomic DNA copy number alterations and transcriptional expression in hepatitis B virus-associated hepatocellular carcinoma. FEBS Lett 2006; 580: 3571-81. http://dx.doi.org/10.1016/j.febslet.2006.05.032

[7] MOINZADEH P, BREUHAHN K, STUTZER H, SCHIRMACHER P. Chromosome alterations in human hepatocellular carcinomas correlate with aetiology and histological grade-results of an explorative CGH meta-analysis. Br J Cancer 2005; 92: 935-41. http://dx.doi.org/10.1038/sj.bjc.6602448

[8] KATOH H, SHIBATA T, KOKUBU A, OJIMA H, LOUKOPOULOS P, et al. Genetic profile of hepatocellular carcinoma revealed by array-based comparative genomic hybridization: identification of genetic indicators to predict patient outcome. J Hepatol 2005; 43: 863-74. http://dx.doi.org/10.1016/j. jhep.2005.05.033

[9] KUSANO N, OKITA K, SHIRAHASHI H, HARADA T, SHIRAISHI K, et al. Chromosomal imbalances detected by comparative genomic hybridization are associated with outcome of patients with hepatocellular carcinoma. Cancer 2002; 94: 746-51. http://dx.doi.org/10.1002/cncr.10254

[10] QI LN, LI LQ, CHEN YY, CHEN ZH, BAI T, et al. Genomewide and differential proteomic analysis of hepatitis $\mathrm{B}$ virus and aflatoxin B1 related hepatocellular carcinoma in Guangxi, China. PLoS One 2013; 8: e83465. http://dx.doi.org/10.1371/ journal.pone. 0083465

[11] WENNMALM K, CALZA S, PLONER A, HALL P, BJOHLE $\mathrm{J}$, et al. Gene expression in $16 \mathrm{q}$ is associated with survival and differs between Sorlie breast cancer subtypes. Genes Chromosomes Cancer 2007; 46: 87-97. http://dx.doi.org/10.1002/ gcc. 20392
[12] LIU X, CHU KM. E-cadherin and gastric cancer: cause, consequence, and applications. Biomed Res Int 2014; 2014: 637308. http://dx.doi.org/10.1155/2014/637308

[13] HUANG C, TIAN Y, PENG R, ZHANG C, WANG D, et al. Association of downregulation of WWOX with poor prognosis in patients with intrahepatic cholangiocarcinoma after curative resection. J Gastroenterol Hepatol 2015; 30: 421-33. http://dx.doi.org/10.1111/jgh.12722

[14] NATRAJAN R, WILLIAMS RD, HING SN, MACKAY A, REIS-FILHO JS, et al. Array CGH profiling of favourable histology Wilms tumours reveals novel gains and losses associated with relapse. J Pathol 2006; 210: 49-58. http://dx.doi. org/10.1002/path.2021

[15] HURST CD, PLATT FM, TAYLOR CF, KNOWLES MA. Novel tumor subgroups of urothelial carcinoma of the bladder defined by integrated genomic analysis. Clin Cancer Res 2012; 18: 5865-77. http://dx.doi.org/10.1158/1078-0432.CCR-121807

[16] BREKKE HR, RIBEIRO FR, KOLBERG M, AGESEN TH, LIND GE, et al. Genomic changes in chromosomes 10, 16, and $\mathrm{X}$ in malignant peripheral nerve sheath tumors identify a high-risk patient group. J Clin Oncol 2010; 28: 1573-82. http://dx.doi.org/10.1200/JCO.2009.24.8989

[17] HATTINGER CM, POTSCHGER U, TARKKANEN M, SQUIRE J, ZIELENSKA M, et al. Prognostic impact of chromosomal aberrations in Ewing tumours. Br J Cancer 2002; 86: 1763-9. http://dx.doi.org/10.1038/sj.bjc.6600332

[18] SUZUKI S, MOORE DH, 2ND, GINZINGER DG, GODFREY TE, BARCLAY J, et al. An approach to analysis of large-scale correlations between genome changes and clinical endpoints in ovarian cancer. Cancer Res 2000; 60: 5382-5.

[19] STEPHAN EA, CHUNG TH, GRANT CS, KIM S, VON HOFF DD, et al. Adrenocortical carcinoma survival rates correlated to genomic copy number variants. Mol Cancer Ther 2008; 7: 425-31. http://dx.doi.org/10.1158/1535-7163. MCT-07-0267

[20] VAN WIER S, BRAGGIO E, BAKER A, AHMANN G, LEVY $\mathrm{J}$, et al. Hypodiploid multiple myeloma is characterized by more aggressive molecular markers than non-hyperdiploid multiple myeloma. Haematologica 2013; 98: 1586-92. http:// dx.doi.org/10.3324/haematol.2012.081083

[21] ROYLANCE R, GORMAN P, PAPIOR T, WAN YL, IVES M, et al. A comprehensive study of chromosome $16 \mathrm{q}$ in invasive ductal and lobular breast carcinoma using array CGH. Oncogene 2006; 25: 6544-53. http://dx.doi.org/10.1038/ si.onc. 1209659

[22] NORDGARD SH, JOHANSEN FE, ALNAES GI, BUCHER E, SYVANEN AC, et al. Genome-wide analysis identifies 16q deletion associated with survival, molecular subtypes, mRNA expression, and germline haplotypes in breast cancer patients. Genes Chromosomes Cancer 2008; 47: 680-96. http://dx.doi. org/10.1002/gcc.20569

[23] KLUSSMANN JP, MOOREN JJ, LEHNEN M, CLAESSEN SM, STENNER M, et al. Genetic signatures of HPV-related and unrelated oropharyngeal carcinoma and their prognostic implications. Clin Cancer Res 2009; 15: 1779-86. http://dx.doi. org/10.1158/1078-0432.CCR-08-1463 
[24] SUNG JS, PARK KH, KIM YH. Genomic alterations of chromosome region $11 \mathrm{p}$ as predictive marker by array comparative genomic hybridization in lung adenocarcinoma patients. Cancer Genet Cytogenet 2010; 198: 27-34. http://dx.doi. org/10.1016/j.cancergencyto.2009.12.001

[25] ADELAIDE J, FINETTI P, BEKHOUCHE I, REPELLINI L, GENEIX J, et al. Integrated profiling of basal and luminal breast cancers. Cancer Res 2007; 67: 11565-75. http://dx.doi. org/10.1158/0008-5472.CAN-07-2536

[26] KIANMANESH R, REGIMBEAU JM, BELGHITI J. Selective approach to major hepatic resection for hepatocellular carcinoma in chronic liver disease. Surg Oncol Clin N Am 2003; 12: 51-63. http://dx.doi.org/10.1016/S1055-3207(02)00090-X

[27] CHEN YJ, YEH SH, CHEN JT, WU CC, HSU MT, et al. Chromosomal changes and clonality relationship between primary and recurrent hepatocellular carcinoma. Gastroenterology 2000; 119: 431-40. http://dx.doi.org/10.1053/gast.2000.9373

[28] ZHAO X, LUO J, LI B, LIU S, LI D. The Association between Preoperative Serum C-Reactive Protein and Hepatocellular Carcinoma Recurrence in Patients with Chronic Hepatitis B Virus (HBV) Infection-A Retrospective Study. PLoS One 2015; 10: e0116909. http://dx.doi.org/10.1371/journal.pone.0116909

[29] LI SH, GUO ZX, XIAO CZ, WEI W, SHI M, et al. Risk factors for early and late intrahepatic recurrence in patients with single hepatocellular carcinoma without macrovascular invasion after curative resection. Asian Pac J Cancer Prev 2013; 14: 4759-63. http://dx.doi.org/10.7314/APJCP.2013.14.8.4759

[30] CHIO, II, SASAKI M, GHAZARIAN D, MORENO J, DONE $\mathrm{S}$, et al. TRADD contributes to tumour suppression by regulating ULF-dependent p19Arf ubiquitylation. Nat Cell Biol 2012; 14: 625-33. http://dx.doi.org/10.1038/ncb2496

[31] TERTIPIS N, HAEGGBLOM L, NORDFORS C, GRUN N, NASMAN A, et al. Correlation of LMP10 expression and clinical outcome in Human Papillomavirus (HPV) positive and HPV-Negative tonsillar and base of tongue cancer. PLoS One 2014; 9: e95624. http://dx.doi.org/10.1371/journal. pone.0095624

[32] NAKAMURA S, YOKOTA D, TAN L, NAGATA Y, TAKEMURA T, et al. Down-regulation of Thanatos-associated protein 11 by BCR-ABL promotes CML cell proliferation through c-Myc expression. Int J Cancer 2012; 130: 1046-59. http://dx.doi.org/10.1002/ijc.26065

[33] ZHU CY, LI CY, LI Y, ZHAN YQ, LI YH, et al. Cell growth suppression by thanatos-associated protein 11(THAP11) is mediated by transcriptional downregulation of c-Myc. Cell Death Differ 2009; 16: 395-405. http://dx.doi.org/10.1038/ cdd.2008.160

[34] LIAN WX, YIN RH, KONG XZ, ZHANG T, HUANG XH, et al. THAP11, a novel binding protein of PCBP1, negatively regulates CD44 alternative splicing and cell invasion in a human hepatoma cell line. FEBS Lett 2012; 586: 1431-8. http:// dx.doi.org/10.1016/j.febslet.2012.04.016

[35] MARSHALL AD, BAILEY CG, RASKO JE. CTCF and BORIS in genome regulation and cancer. Curr Opin Genet Dev 2014; 24: 8-15. http://dx.doi.org/10.1016/j.gde.2013.10.011

[36] FILIPPOVA GN, LINDBLOM A, MEINCKE LJ, KLENOVA EM, NEIMAN PE, et al. A widely expressed transcription factor with multiple DNA sequence specificity, CTCF, is localized at chromosome segment $16 \mathrm{q} 22.1$ within one of the smallest regions of overlap for common deletions in breast and prostate cancers. Genes Chromosomes Cancer 1998; 22: 26-36. http:// dx.doi.org/10.1002/(SICI)1098-2264(199805)22:1<26::AIDGCC4>3.0.CO;2-9

[37] ISHII H, SAITOH M, SAKAMOTO K, KONDO T, KATOH $\mathrm{R}$, et al. Epithelial splicing regulatory proteins 1 (ESRP1) and 2 (ESRP2) suppress cancer cell motility via different mechanisms. J Biol Chem 2014; 289: 27386-99. http://dx.doi. org/10.1074/jbc.M114.589432

[38] GABROVSKA PN, SMITH RA, TIANG T, WEINSTEIN SR, HAUPT LM, et al. Development of an eight gene expression profile implicating human breast tumours of all grade. Mol Biol Rep 2012; 39: 3879-92. http://dx.doi.org/10.1007/s11033$\underline{011-1167-6}$

[39] KATKOORI VR, SHANMUGAM C, JIA X, VITTA SP, STHANAM M, et al. Prognostic significance and gene expression profiles of $\mathrm{p} 53$ mutations in microsatellite-stable stage III colorectal adenocarcinomas. PLoS One 2012; 7: e30020. http://dx.doi.org/10.1371/journal.pone.0030020 